\title{
LATAM-ICCRom (2008-2019): Programa para la Conservación del Patrimonio Cultural en América Latina y el Caribe
}

ICCROM

\author{
Introducción
}

CCROM $^{1}$ es un organismo intergubernamental dedicado a la conservación del patrimonio cultural -la única institución con el mandato específico de alentarla- tanto mueble como inmueble. Sus objetivos principales incluyen promover la calidad de las prácticas de la conservación e incrementar la sensibilización sobre la importancia de preservar nuestro legado patrimonial.

ICCROM contribuye a conservar el patrimonio cultural, tanto para las sociedades actuales como para las generaciones futuras, a través de cinco áreas de actividad: capacitación, información, investigación, cooperación y sensibilización.

A lo largo de sus cinco décadas de existencia, ICCROM ha desarrollado diferentes estrategias para cumplir con su mandato de la manera más eficiente posible, tomando en cuenta los reducidos tamaños de la organización y de su presupuesto. En los últimos 20 años, sus actividades se diversificaron, por una parte, con el seguimiento de cursos y actividades de carácter internacional y, por la otra, con los programas concebidos para responder a las necesidades y a los recursos de determinadas regiones geográficas. Así nacieron en su momento los programas PREMA 1990-2000, AFRICA 2009, COIlASIA 2010 y ATHAR. LATAM es el más joven de ellos: se trata de un programa de 12 años de duración que tiene como objetivos principales mejorar y fortalecer las capacidades de los profesionales del sector de la conservación del patrimonio cultural en América Latina y el Caribe, así como mejorar la comunicación y el intercambio en la región e incrementar la sensibilización de una vasta audiencia respecto de la necesidad de proteger ese patrimonio.

¿Por qué LATAM?

La región objetivo de LATAM posee una gran riqueza de diferentes expresiones culturales que abarcan miles de años. Esta porción significativa del patrimonio mundial es un recurso importante para la cohesión social y el desarrollo en la región, pero requiere una conservación y un uso sostenibles. Como ocurre con el patrimonio de muchas otras partes del mundo, el de América Latina y el Caribe corren el riesgo de degradaciones o pérdidas irreversibles, a causa de varios factores que incluyen los impactos: ambiental, debido al incremento en los niveles de contaminación y al cambio climático; de desarrollo económico,

\footnotetext{
${ }^{1}$ International Centre for the Study of the Preservation and Restoration of Cultural Property.
} 
originado, entre otros, por el crecimiento urbano y el turismo; de la globalización, que lleva a una pérdida de identidad, así como al saqueo y al tráfico ilícito de bienes culturales.

Aunque existen iniciativas en curso, así como un alto grado de experiencia en los países de la región para enfrentar las cuestiones antes mencionadas, por lo general se ha tratado de esfuerzos aislados, distribuidos en ella de manera desigual. Así, el Programa LATAM se diseñó para crear un mayor acercamiento y diálogo que permita integrar y armonizar los esfuerzos de conservación en la zona, ya sea a través del trabajo con profesionales e instituciones en ella o mediante la creación de sinergias, el reagrupamiento de experiencias, la identificación de áreas de acción comunes, la contribución de herramientas para una mayor colaboración entre sectores del patrimonio, así como el desarrollo de mecanismos tanto para una mayor movilidad profesional como para una mayor autosuficiencia.

\section{Principios orientadores de LATAM}

Los principios orientadores del programa, que se definieron tomando en consideración la situación general de la conservación del patrimonio cultural en América Latina y el Caribe, consisten en:

- Enfocar el programa hacia diferentes grupos de beneficiarios y audiencias para tener la mayor cobertura posible de profesionales del patrimonio y de otros grupos de interés.

- Auspiciar la inclusión de distintos grupos de interés y favorecer actividades interdisciplinarias e intersectoriales.

- Tener una amplia participación, representación y distribución geográficas, así como una rotación de sedes para desarrollar las actividades, que permita equilibrar paulatinamente las desigualdades de la región en materia de conservación del patrimonio.

- Involucrar y emplear al máximo las estructuras y las capacidades existentes (instituciones públicas y académicas, centros de conservación y profesionales, organizaciones de base) en los diferentes países de la región para la preservación y promoción del patrimonio.

- Favorecer y fortalecer el vínculo con las universidades, centros de investigación y programas de formación existentes para asegurar mayor sostenibilidad y transferencia de la inversión realizada.

- Alentar el diálogo e intercambio entre modelos y directrices internacionales, y de experiencias y contextos específicos en la región.

- Sostener un intercambio permanente de experiencias y ampliar las redes de comunicación y contacto entre profesionales e instituciones de la región e incluso más allá.

- Promover más actividades en español.

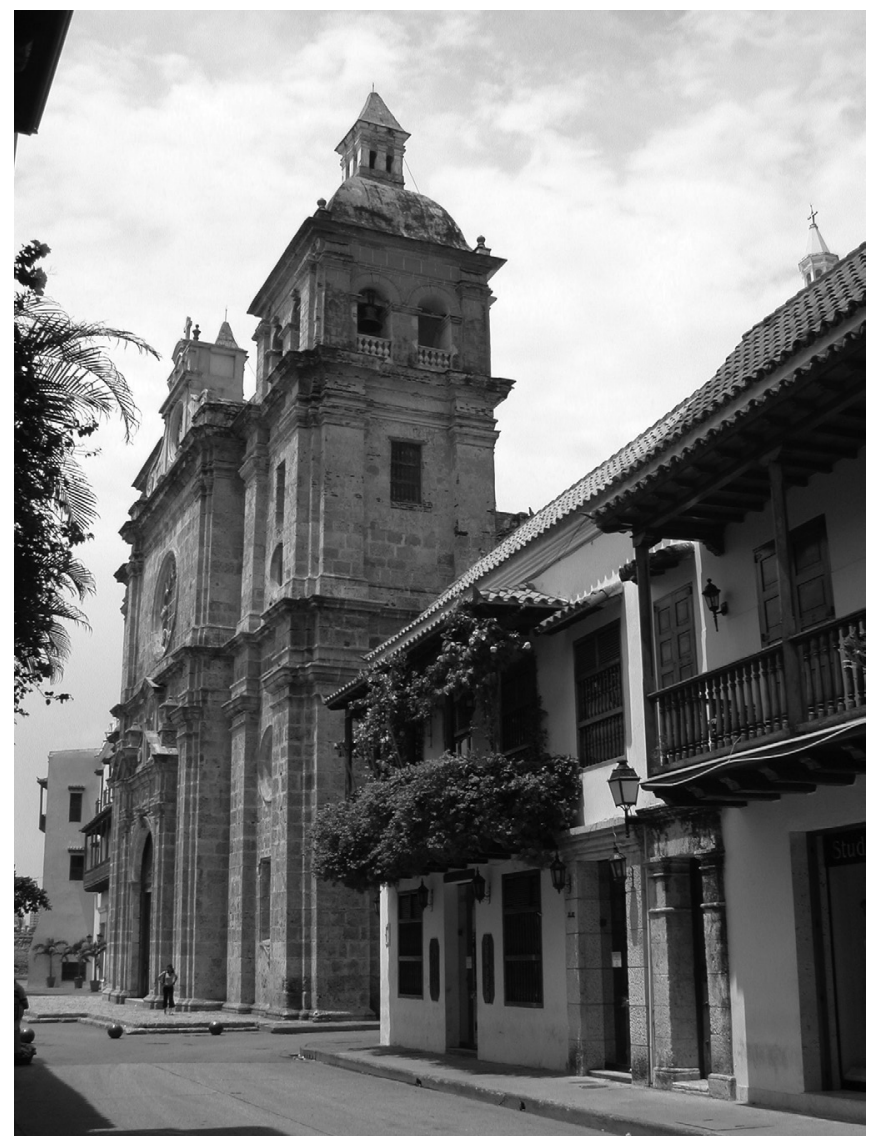

FIGURA 1. Calle de Cartagena de Indias, Colombia. (Fotografía, cortesía de Valerie Magar Meurs).

\section{Un acercamiento programático}

LATAM fue diseñado siguiendo un modelo programático, que inició con una evaluación de necesidades a escala regional y continuó con la formulación de metas y objetivos que llevarán a resultados sostenibles.

Para la fase inicial del programa (2008-2011) se formaron con profesionales de la conservación, cinco grupos de trabajo; el objetivo es que éstos abarquen cada vez más países, instituciones y profesionales:

- Educación y formación

- Tráfico ilícito de bienes culturales

- Indicadores económicos para la conservación

- Gestión de riesgos

- Información y documentación

El principio guía de este programa es establecer un marco programático amplio que contenga las actividades individuales de los grupos de trabajo y asegure que el total sea mayor que la suma de las partes. ${ }^{2}$ Se espera que

\footnotetext{
${ }^{2}$ Véase información adicional y actualizada sobre las actividades y la estructura de LATAM en la página web de ICCROM: [www.iccrom.org].
} 
conforme LATAM avance, se creen nuevos grupos, para hacer frente a las diferentes necesidades.

De la misma manera que para los otros programas regionales de ICCROM, los recursos financieros para éste provendrán de presupuestos adicionales. El éxito de LATAM requerirá el apoyo, a través de la aportación de recursos financieros, humanos y técnicos, de todos los países miembros de ICCROM, en particular de aquellos que constituyen la zona. En ésta, que tiene aún numerosos retos por delante, ICСROм sabe del alto potencial de profesionales de excelente calidad para poder Ilevar LATAM hacia delante.

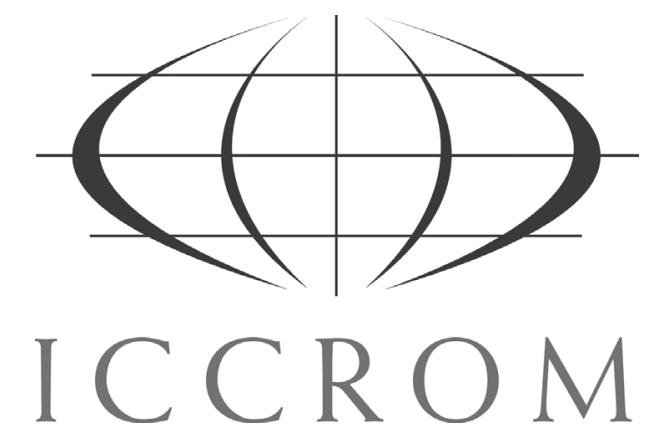

FIGURA 2. Logo de ICCROM.

\section{Resumen}

ICCROM, un organismo intergubernamental dedicado a la conservación del patrimonio cultural, ha enfocado una parte de sus esfuerzos en la realización de programas regionales para hacer frente a necesidades y oportunidades específicas. En 2008 se lanzó el más reciente de sus programas, LATAM, para la conservación del patrimonio cultural en América Latina y el Caribe. Se presentan aquí sus objetivos y actividades iniciales.

\section{Palabras clave}

ICCROM, programas regionales, LATAM, Latinoamérica y el Caribe.

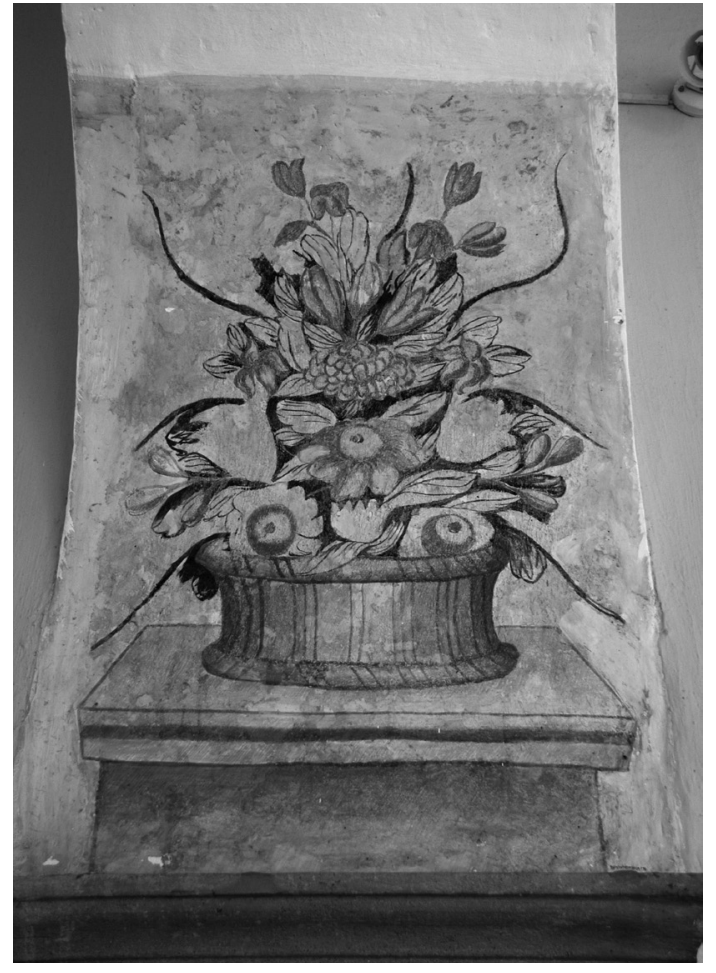

FIGURA 3. Pintura mural del Convento de San Francisco, Quito, Ecuador. (Fotografía, cortesía de Valerie Magar Meurs).

\section{Abstract}

ICCROM, an intergovernmental organization dedicated to the conservation of cultural heritage worldwide, has focused part of its activities in developing regional programmes, in order to meet specific needs and opportunities. In 2008, it launched its most recent programme, LATAM, dedicated to the conservation of cultural heritage in Latin America and the Caribbean. This short text shows LATAM's objectives and initial activities.

\section{Keywords}

ICCROM, Regional programmes, LATAM, Latin America and the Caribbean 